\title{
Structural Studies of the Complex Between Akt-in and the Akt2-PH Domain Suggest that the Peptide Acts as an Allosteric Inhibitor of the Akt Kinase
}

\author{
Virginie Ropars ${ }^{1,2,3}$, Philippe Barthe ${ }^{1,2,3}$, Chi-Shien Wang ${ }^{4}$, Wenlung Chen ${ }^{4}$, Der-Lii M. Tzou ${ }^{4,5}$, \\ Anne Descours ${ }^{6}$, Loïc Martin ${ }^{6}$, Masayuki Noguchi ${ }^{7}$, Daniel Auguin ${ }^{1,2,3, \text {, }}$ and \\ Christian Roumestand ${ }^{*}, 1,2,3$
}

${ }^{I}$ CNRS UMR 5048, Centre de Biochimie Structurale, Montpellier, France

${ }^{2}$ INSERM U554, Montpellier, France

${ }^{3}$ Université Montpellier I et II, Montpellier, France

${ }^{4}$ Department of Applied Chemistry, National Chiayi University, Chiayi 60004, Taiwan, ROC

${ }^{5}$ Institute of Chemistry, Academia Sinica, Nankang, Taipei 11529, Taiwan, ROC

${ }^{6}$ CEA, iBiTecs, Service d'Ingénierie Moléculaire des Protéines, 91191 Gif sur Yvette, France

${ }^{7}$ Division of Cancer Biology, Institute for Genetic Medicine, Hokkaido University, N15 W7, Kita-ku, Sapporo 060-0815, Japan

\begin{abstract}
Serine/threonine kinase Akt plays a central role in the regulation of cell survival and proliferation. Hence, the search for Akt specific inhibitors constitutes an attractive strategy for anticancer therapy. We have previously demonstrated that the proto-oncogene TCL1 coactivates Akt upon binding to its Plekstrin Homology Domain, and we proposed a model for the structure of the complex TCL1:Akt2-PHD. This model led to the rational design of Akt-in, a peptide inhibitor spanning the A $B$-strand of human TCL1 that binds Akt2 PH domain and inhibits the kinase activation.

In the present report, we used NMR spectroscopy to determine the 3D structure of the peptide free in solution and bound to Akt2-PHD. NMR chemical shift mapping was used to determine the imprint of Akt-in on the PH domain; whereas peptide Ala-scanning revealed which peptide residues were involved in the interaction. Together with the solution structure of Akt2-PHD, these results allowed us to dock Akt-in on the PH domain. The docked complex suggests that while Akt-in binds Akt2-PHD in a region overlapping the binding site of TCL1, its mode of interaction is markedly different. Moreover, the affinity was disappointingly low, contrary to that published previously.

Besides providing a description of the interaction between Akt-in an Akt2 PH domain, the present work brings additional clues on the putative peptide mode of action. Instead of behaving as an analog of PtdIns, as previously suggested, Akt-in might act as an "allosteric" inhibitor, maintaining the full-length kinase in its "closed" inactive conformation, rather than disturbing the membrane anchorage of its "open" active conformation.
\end{abstract}

Keywords: Akt, PKB, pleckstrin homology domain, apoptosis, cancer, peptide inhibitor, NMR, solution structure.

\section{INTRODUCTION}

Akt plays a central role in the regulation of several signaling pathways controlling cell survival and proliferation. To date, three mammalian isoforms (Akt1/Protein Kinase $\mathrm{B} \alpha$ $[\mathrm{PKB} \alpha], \mathrm{Akt} 2 / \mathrm{PKB} \beta$, and $\mathrm{Akt} 3 / \mathrm{PKB} \gamma)$ of the kinase have been identified that share a high degree of sequence and structural

*Address correspondence to this author at the Centre de Biochimie Structurale, 29, rue de Navacelles, 34090 Montpellier Cedex 6, France; Tel: +33(0) 467417 704; Fax: +33 (0) 467417 913;

E-mail: christian.roumestand@cbs.cnrs.fr

'Present Address: Université d'Orléans, UFR-Faculté des Sciences, Laboratoire de Biologie des Ligneux et des Grandes Cultures, UPRES EA 1207, rue de Chartres, BP 6759, 45067 Orléans Cedex 02, France ${ }^{\text {ii }}$ INRA, USC2030 'Arbres et Réponses aux Contraintes Hydrique et Environnementales' (ARCHE), F-45067 Orléans Cedex 02, France homology, even though a possible distinct role has been suggested for each of them [1-4]. The kinases have two distinct functional domains: an $\mathrm{N}$-terminal pleckstrin homology domain (PHD) mediating protein-protein and protein-lipid interactions and a C-terminal catalytic domain [5-7]. The basic activation process of the Akt isoforms appears to be uniform [8]. After the binding of growth factors to their cell-surface receptors, Akt is translocated to the plasma membrane following the binding of the $\mathrm{PH}$ domain to the products of the phosphoinositide-3-kinase pathway: phosphatidylinositide(PI)-3,4-biphosphate and PI$3,4,5$ triphosphate $[5,7,9]$. The regulation of Akt is then regulated by phosphorylation on two regulatory sites, threonine 308/309/305 and serine 473/474/472 (Akt1/2/3, respectively), with phosphorylation of both required for maximal kinase activity [10]. Phosphorylation of the threonine residue occurs via the activity of phosphoinositide-dependent kinase (PDK1) $[6,7,11]$. The exact mechanism for the phosphorylation of the 
serine residue remains to be deciphered [7, 12, 13]. Over 20 molecules have been identified as potential physiological substrates of Akt, including GSK $3 \alpha$ (glycogen synthesis kinase $3 \alpha$ ), GSK3 $\beta$, BAD, endothelial nitric-oxid synthase, and forkhead transcription factor (FHKR) [5, 14].

The PI3K-Akt signaling pathway regulates many normal cellular processes, including cell proliferation, survival, growth and motility, processes that are critical for tumorogenesis. Indeed, the role of this pathway in oncogenesis has been extensively investigated and altered expression or mutations of many components of this pathway have been implicated in human cancer [15]. Thus, the kinase Akt represents an attractive target for drug development [4, 16]. We have previously shown that a peptide spanning the TCL1 Akt binding site inhibited Akt membrane translocation, along with its downstream biological responses [17]. The proto-oncogene TCL1 (T Cell Leukemia 1) protein family was first identified in the translocation of human $\mathrm{T}$ cell prolymphocytic leukemia ( $\mathrm{T}$ PLL), a rare form of adulthood leukemia [18, 19]. Three isoforms have been subsequently identified in the human genome: TCL1, TCL1b, and MTCP1 (mature T cell proliferation) [20], which share a high sequence homology and a similar 3D structure. Interestingly, MTCP1 [21, 22] and possibly TCL1b for which only a $3 \mathrm{D}$ model of its structure is available [23] - is monomeric in solution, whereas TCL1 forms a tight dimer in the crystal and in solution [24]. In yeast screening of Akt to search for an interacting partner, we have demonstrated that TCL1 interacts with the $\mathrm{PH}$ domain of Akt. This interaction was functional, since we and others have shown that TCL1 enhances Akt kinase activity, and therefore functions as an Akt kinase coactivator $[25,26]$. NMR and SAXS studies further supported the structural basis of this interaction, yielding the precise definition of the mutual protein binding sites $[27,28]$. Whether the oncogenic role of TCL1 is uniquely related to the co-activation of Akt is still under debate [29, 30]. Nevertheless, using the structural model obtained for the complex TCL1:Akt2 PH domain, we hypothesized and verified that the peptide Akt-in spanning the TCL1 Akt binding site (encompassing the $\beta \mathrm{A}$ strand) binds to Akt and modulates Akt kinase activity.

In order to establish the structural basis of the mechanism of action of $A k t$-in, we present here the structural study of this peptide inhibitor free in solution and bound to the Akt2 $\mathrm{PH}$ domain (Akt2-PHD). The binding site of Akt-in on Akt2-PHD was established using the NMR chemical shift perturbation technique, while the inhibitor binding site recognized by Akt2PHD was obtained through Ala-scanning of the peptide coupled with NMR titration. From these data, we obtained a model of the Akt2-PHD:Akt-in complex using HADDOCK calculations. Based on the results from this study, we suggest a novel mechanism of action for the inhibition of the kinase Akt by the peptide inhibitor.

\section{MATERIAL AND METHODS}

\section{Protein Preparation}

The production of the recombinant Akt2 Pleckstrin Homology domain has been published in detail elsewhere [28]. Briefly, Akt2-PHD was amplified by PCR from human EBV transformed B cell cDNA library. The cDNA encoding the $111 \mathrm{~N}$-terminal residues of human Akt2 - corresponding to the Pleckstrin Homology domain - was sub-cloned into the EcoRI BamHI sites of the pGEX2T plasmid. Uniformly labeled ${ }^{15} \mathrm{~N}$ recombinant protein was obtained from overexpression in $E$. coli BL21 grown in minimal medium containing ${ }^{15} \mathrm{NH}_{4} \mathrm{Cl}$ as the sole nitrogen source. The GSTfusion protein was purified using affinity chromatography on glutathione-sepharose beads (Pharmacia), and then cleaved overnight by adding thrombin to the beads in a low salt buffer. Eluted protein was further purified using size exclusion chromatography with an HR100 column (Pharmacia). The different preparations yield about $15 \mathrm{mg}$ of each protein (unlabeled and ${ }^{15} \mathrm{~N}$-labeled) that were conditioned at a concentration of $0.1 \mathrm{mM}$ in the buffer used for NMR spectroscopy (10 mM Tris/ $\mathrm{HCl}(\mathrm{pH} 7.4), 300 \mathrm{mM}$ $\mathrm{NaCl}, 0.1 \mathrm{mM}$ benzamidine, $0.1 \mathrm{mM}$ EDTA).

\section{Peptide Synthesis}

The peptide Akt-in, that corresponds to the BA strand of TCL1, and the 13 Ala-scan peptide sequences were synthesized in an automated, solid-phase peptide synthesizer 433A (Applied Biosystems, Stafford, Texas), using Fmoc chemistry and PyBOP activation. In this series, the non-Ala amino acids in the Akt-in sequence $\left(\mathrm{CH}_{3} \mathrm{CO}-\mathrm{NH}-\right.$ AVTDHPDRLWAWEKF-CONH 2 ) were replaced by Ala systematically. Besides this series, other peptides corresponding to the $\mathrm{BA}$ strand of $\mathrm{MTCP} 1\left(\mathrm{CH}_{3} \mathrm{CO}-\mathrm{NH}-\right.$ GAPPDHLWVHQEG-CONH$\left.{ }_{2}\right)$ or TCL1b $\left(\mathrm{CH}_{3} \mathrm{CO}-\mathrm{NH}-\right.$ GVPPGRLWIQRPG-CONH${ }_{2}$ ), two other members of the TCL1 proto-oncogene family, were also synthesized, as well as the control peptide corresponding to the $\mathrm{BC}$ strand of TCL1 $\left(\mathrm{CH}_{3} \mathrm{CO}-\mathrm{NH}-E K Q H A W L P L T I E-\mathrm{CONH}_{2}\right)$. The peptide products were purified by HPLC using a reverse phase C-18 column (SUPELCO, $250 \mathrm{~mm}$ x $10 \mathrm{~mm}$, 5um) on an Anglient 1100 system. Purity and homogeneity were confirmed by MALDI-TOF mass spectrometry. All mass spectra were acquired using a MALDI-TOF mass spectrometer (Voyager DE-PRO, Applied Biosystem, Foster City, CA) equipped with a $337 \mathrm{~nm}$ nitrogen laser. The spectra were recorded in the linear mode using an accelerating voltage of $25 \mathrm{kV}$, a $91 \%$ grid voltage, $0.1 \%$ guide wire voltage, and $100 \mathrm{~ns}$ delay time. The matrix acyano-4-hydroxycinnamic acid (CHCA) was directly mixed with $1 \mathrm{ml}$ of target, spotted onto the sample plate, air-dried, and analyzed.

\section{Circular Dichroism Analysis}

The peptide concentrations were determined using a ND1000 Spectrophotometer (NanoDrop Technologies) and extinction coefficients obtained from sequence analysis using the ProtParam tool from the ExPASy server (http://www.expasy.ch/tools/protparam.html). Far UV-CD spectra were recorded with a chirascan dichrograph (Applied Photophysics) in a thermostated $\left(20^{\circ} \mathrm{C}\right)$ quartz circular cell with a $0.5 \mathrm{~mm}$ path length, in steps of $0.5 \mathrm{~nm}$. All protein spectra were corrected by subtraction of the buffer spectra. The mean molar ellipticity values per residue were calculated using the manufacturer software.

\section{NMR Spectroscopy and Structure Calculations}

All NMR experiments were carried out either at 500 or 600 $\mathrm{MHz}$, on Bruker Avance II spectrometers equipped with z- 
gradient ${ }^{1} \mathrm{H}-{ }^{13} \mathrm{C}-{ }^{15} \mathrm{~N}$ triple resonance cryoprobes. For the study of the peptide free in solution, the sample concentration was 2 $\mathrm{mM}$ in pure water, and the $\mathrm{pH}$ was adjusted to 3 . When studied in the presence of the protein Akt2-PHD (peptide/protein ratio ranking from 10 to 100), the peptide was dissolved in TRIS buffer $(10 \mathrm{mM})$, pH 7.4, $300 \mathrm{mM} \mathrm{NaCl}$. All samples contained $5 \%(\mathrm{v} / \mathrm{v}){ }^{2} \mathrm{H}_{2} \mathrm{O}$ for the lock. Data were acquired on samples generally maintained at $7^{\circ} \mathrm{C}$, and ${ }^{1} \mathrm{H}$ chemical shifts were directly referenced to the methyl resonance of DSS (EURISOTOP), while ${ }^{13} \mathrm{C}$ and ${ }^{15} \mathrm{~N}$ chemical shifts were referenced indirectly to the absolute frequency ratios ${ }^{15} \mathrm{~N} /{ }^{1} \mathrm{H}=$ 0.101329118 and ${ }^{13} \mathrm{C} /{ }^{1} \mathrm{H}=0.251449530$. In all $2 \mathrm{D}$ experiments, quadrature detection in the indirectely observed dimension was obtained with States-TPPI [31]. The data sets were processed using XWINNMR software.

Homonuclear spectroscopy. NOESY [32, 33] experiments (transferred nOe) were recorded with mixing times ranking from 100 to $500 \mathrm{~ms}$. When recorded in the presence of Akt2-PHD, an isotopic filter [34] was added to the basic sequence in order to suppress proton amide resonances from the protein. Off-resonance ROESY [35] was recorded with a $5 \mathrm{kHz}$ adiabatic pulse of $200 \mathrm{~ms}$ length, applied with an offset angle of 54. z-TOCSY [36-38] experiments were carried out using a $80 \mathrm{~ms}$ TOWNY isotropic transfer sequence [39], at a field strength of $10 \mathrm{kHz}$ (corresponding to a $\pi$ pulse of $50 \mu \mathrm{s}$ ). Solvent suppression was carried out using the excitation-sculpting method [40].

Heteronuclear spectroscopy. Owing to the high sensitivity allowed by the use of cryogenic probes, the peptide ${ }^{15} \mathrm{~N}$ and ${ }^{13} \mathrm{C}$ resonances were assigned from $2 \mathrm{D}$ experiments conducted at natural isotope abundance. $\left[{ }^{1} \mathrm{H}\right.$, $\left.{ }^{15} \mathrm{~N}\right] 2 \mathrm{D}$ HSQC $[41,42]$ were recorded in $\mathrm{H}_{2} \mathrm{O}$ using a time domain data size of $64 \mathrm{t}_{1} * 512 \mathrm{t}_{2}$ complex points and 256 transients per complex $\mathrm{t}_{1}$ increment. $\left[{ }^{1} \mathrm{H},{ }^{13} \mathrm{C}\right] 2 \mathrm{D}$ HSQC, $\left[{ }^{1} \mathrm{H},{ }^{13} \mathrm{C}\right]$ 2D HSQC-TOCSY [43] spectra were recorded in ${ }^{2} \mathrm{H}_{2} \mathrm{O}$ using time domain data sizes of $200 \mathrm{t}_{1} * 1024 \mathrm{t}_{2}$ complex points, and 32 and 96 transients per complex $t_{1}$ increment, respectively. As for homonuclear 2D TOCSY, the TOWNY sequence was used for isotropic mixing $(80 \mathrm{~ms})$ in the 2D HSQC-TOCSY.

NMR Titration Experiments. $K_{D}$ values were obtained from the fit of chemical shift variations measured on a series of $\left[{ }^{1} \mathrm{H},{ }^{15} \mathrm{~N}\right] \mathrm{HSQC}$ spectra on a $100 \mu \mathrm{M}{ }^{15} \mathrm{~N}$-labeled Akt2PHD sample as a function of the ligand concentration with the following equation:

$$
\Delta \delta=\frac{1}{2} \Delta \delta_{\max }\left[\left(1+\frac{k_{D}}{\left[P_{0}\right]}+\frac{[L]}{\left[P_{0}\right]}\right)-\sqrt{\left(1+\frac{k_{D}}{\left[P_{0}\right]}+\frac{[L]}{\left[P_{0}\right]}\right)^{2}-\frac{4[L]}{\left[P_{0}\right]}}\right]
$$

where $\left[\mathrm{P}_{0}\right]$ is the concentration of ${ }^{15} \mathrm{~N}$-labelled Akt2-PHD $(90 \mu \mathrm{M})$, [L] the variable ligand concentration, $\Delta \delta_{\max }$ the maximum chemical shift variation, and $\Delta \delta$ the cumulative chemical shift variation for the resonances of an amide group after adding the ligand, obtained through:

$\Delta \delta=\sqrt{\left[\Delta \delta\left({ }^{15} N\right) \frac{\gamma_{N}}{\gamma_{H}}\right]^{2}+\left[\Delta \delta\left({ }^{1} H\right)\right]^{2}}$

where $\Delta \delta\left({ }^{1} \mathrm{H}\right)$ is the proton chemical shift change and $\Delta \delta\left({ }^{15} \mathrm{~N}\right)$ is the nitrogen chemical shift change.
Molecular Modeling Calculations. Inter-proton distance restraints obtained from 2D off-resonance ROESY experiments were divided into 5 distance classes, according to their intensities. For equivalent protons or nonstereospecifically assigned protons, pseudo-atoms were introduced. Backbone $\phi$ and $\psi$ torsion angle constraints were obtained from a database search procedure on the basis of backbone $\left({ }^{15} \mathrm{~N}, \mathrm{HN},{ }^{13} \mathrm{C},{ }^{13} \mathrm{C}^{\alpha}, \mathrm{H}^{\alpha},{ }^{13} \mathrm{C}^{\beta}\right)$ chemical shifts using the program TALOS [44]. Among the 400 preliminary structures generated by CYANA 2.1 [45], 20 presented a value of the target function smaller than $0.02 \AA^{2}$, no distance violation, and no violation on the dihedral angles $\phi, \psi$ and $\chi_{1}$. The 20 best structures (based on the final target penalty function values) were further analyzed with PROCHECK [46]. The r.m.s. deviations and visual display were performed with the program MOLMOL [47] (see Table 2).

The coordinate files of these 20 conformers were used as starting structures for the docking of the peptide on Akt2 PH domain with the HADDOCK package [48]. The coordinate files for Akt2-PHD were obtained from the RCBS Protein Data Bank (PDB, 1P6S) [28]. Protein residues located in the predicted interaction interface were defined as "active". These assignments were based on chemical shift mapping data generated via NMR protein/peptide titration. In addition, all active residues exhibit a relative solvent accessibility $>50 \%$ as delineated by the program NACCESS [49]. For the peptide Akt-in, "active" residues were those which replacement by alanine led to a significant decrease in affinity with Akt2-PHD. No residues in the protein, nor in the peptide, were defined as being "passive" (residues with solvent accessibility $\geq 50 \%$ surrounding active residues). Default HADDOCK parameters were used in the docking procedure. Final structures were clustered using the program ProFit (httpp://www.bioinf.org.uk/software/profit/). The resulting clusters were analyzed and ranked according to their average interaction energies.

\section{RESULTS}

\section{Defining Binding Surfaces in the Akt-in: Akt2-PHD Complex}

We used a chemical shift perturbation strategy as previously described [27], to define the binding site of Akt-in on the Akt2PHD surface. In the presence of $A k t-i n$, the main perturbations affect the peptide segment L52-E66, encompassing the Cterminal end of the $\beta 4$ strand, the turn between strands $\beta 4$ and $B 5$, and the whole $\beta 5$ strand of the $\mathrm{PH}$ domain $\beta$-sandwich (Fig. 1). Additional significant perturbations affect the $\mathrm{C}$-terminal helix of the PH domain, wedged between the $\beta 1$ and the $\beta 5$ strands of the $\beta$-sandwhich. Other sparse perturbations are observed for residues I74, I75, linked to the L52-E66 segment via the C69-C77 disulfide bridge, or for the residue F88 deeply buried in the $\beta$ sandwich. Importantly, residues R15, G16, Y18, I19, belonging to the VL1 loop involved in the phosphatidyl inositol phosphate (PtdInsP) binding site, also exhibit significant chemical shift perturbations upon addition of Akt-in.

In contrast, NMR techniques such as STD experiments [50] failed to reveal the Akt-in residues involved in the interaction with the $\mathrm{PH}$ domain, probably because of a low affinity (see below) associated with a relatively low molecular weight for the target protein $(15 \mathrm{kDa})$. Attempts to 


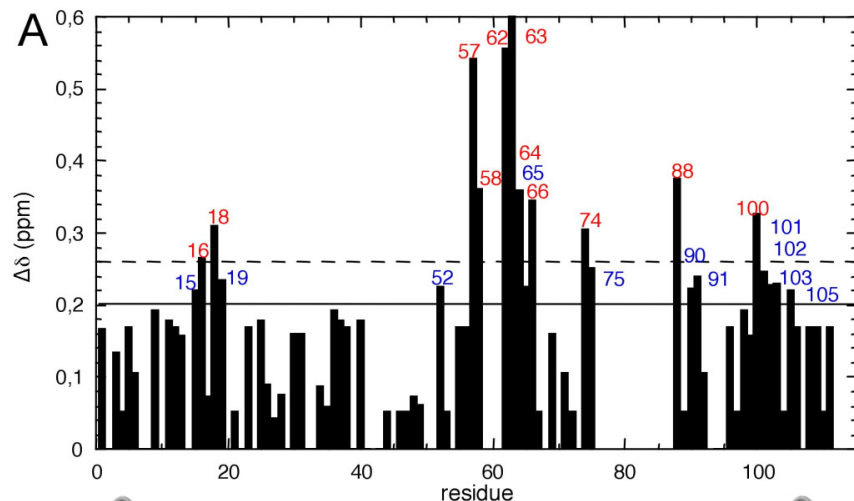

B
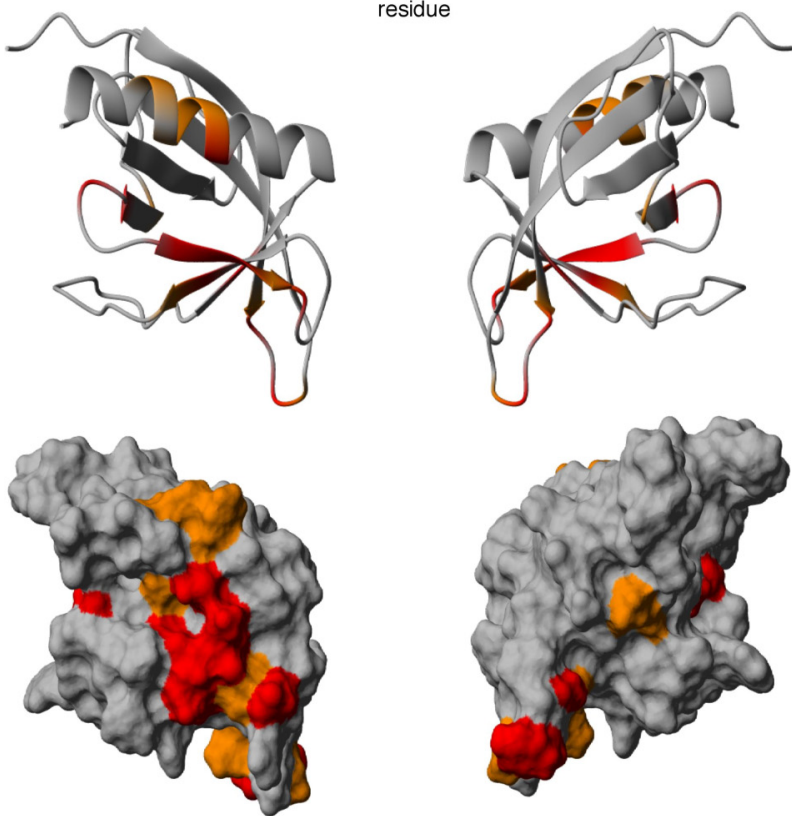

Fig. (1). Results of the chemical shift mapping experiment. (A) Bar charts the cumulative chemical shift variation $\Delta \delta$ against the residue number for ${ }^{15} \mathrm{~N}$-Akt2-PHD $(100 \mu \mathrm{M})$ in the presence of $2 \mathrm{mM}$ of Akt-in inhibitor. Residues exhibiting chemical shift variations beyond $1 \sigma$ and $2 \sigma$ (plain and dotted line, respectively) are indicated with their sequence number in blue or red, respectively. (B) Different views $\left(180^{\circ}\right.$ rotation around the vertical axis) of the NMR three-dimensional structure of Akt2-PHD presented as ribbons (upper panels) or Van der Waals surface diagrams (bottom panels). Colored residues indicate the footprint in the presence of $A k t$-in determined by the NMR mapping: red residues represented significant $(>2 \sigma)$ deviation in the chemical shift of the amide group, orange residues represented a modest $(>1 \sigma)$ shift in the study. Unaffected residues are shown in gray.

use the hybrid construct (GST-Akt2-PHD) in order to increase the molecular weight was also unfruitful, probably because the GST-tag is linked to the C-terminal end of Akt2PHD, masking the Akt-in binding site. Finally, in order to reveal the Akt-in residues engaged in the interaction, the contribution of each side chain of the peptide to Akt2-PHD binding was investigated by systematic mutation of each residue of $A k t$-in to alanine, ie, ala-scan. Each variant peptide was then titrated as described below for Akt-in itself. The $\mathrm{K}_{\mathrm{D}}$ values obtained for all variants - presented relativev to the wild-type peptide $\mathrm{K}_{\mathrm{D}}$ - are reported in Fig. (2). Importantly, CD spectra recorded for each variant indicate that the replacement of any residue with alanine residue does not introduce structural distorsions (data not shown).
Interestingly, the key amino acids were found to be located in the hydrophobic L9-F15 C-terminal segment of Akt-in. Replacing the tryptophan residues by Alanine yields a 5-fold (W10A) to almost a 10-fold (W12A) decrease in affinity. Substituting the C-terminal phenylalanine residue or L9 by Ala yields a smaller decrease in affinity (2-fold to 3-fold, respectively). Consistently, exchanging the charged Cterminal residues $\mathrm{E} 13$ and $\mathrm{K} 14$ with a more hydrophobic alanine residue yields a slight increase in affinity with regard to the wild-type peptide. As a result, the Akt-in binding site consists of the C-terminal hydrophobic residues, among which W12 plays probably a central role in the binding to Akt2-PHD.

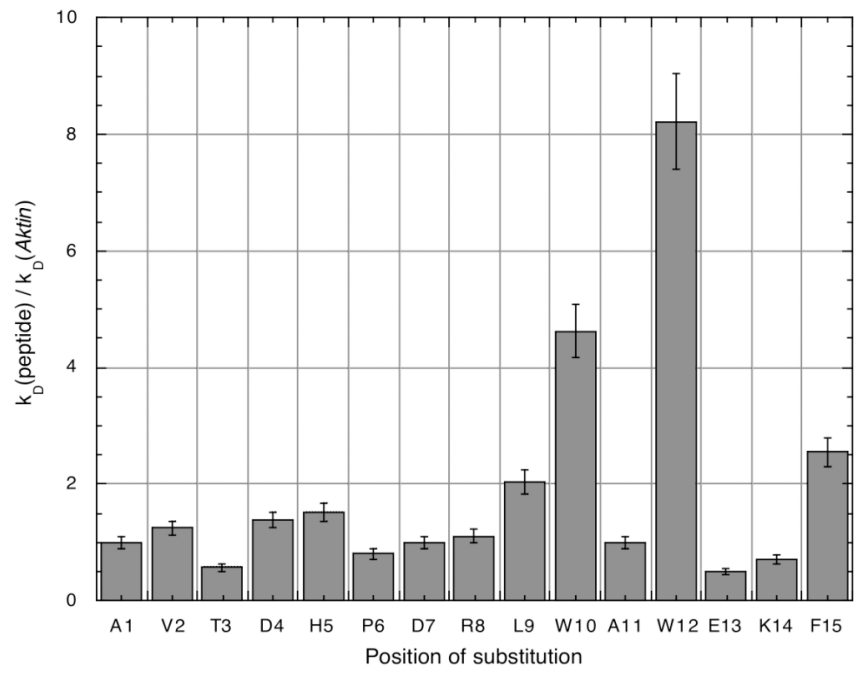

Fig. (2). The role of each amino acid residue in Akt-in when binding to Akt $2 \mathrm{PH}$ domain. Histogram shows the ratio of the $\mathrm{k}_{\mathrm{D}}$ measured for each peptide variant - in which individual amino acids were alanine-substituted - to the $\mathrm{k}_{\mathrm{D}}$ value measured for the "wild-type" Akt-in peptide.

\section{$K_{D}$ Measurements}

A series of HSQC experiments recorded at different Aktin:Akt2-PHD molar ratios were carried out, and the curves were fit for the $K_{D}$ with the equation given in Material and Methods section. The cross-peak corresponding to the amide group of M63, that exhibits the largest chemical shift perturbations, was used as probe for these titrations (Fig. 3). $\mathrm{A} \mathrm{K}_{\mathrm{D}}$ value of $3 \pm 0.7 \mathrm{mM}$ was obtained for the Akt-in:Akt2PHD complex. We measured a $K_{D}$ value of $55 \pm 20 \mathrm{mM}$ for the control peptide corresponding to the $B C$ strand of TCL1 (see Material and Methods). The $\mathrm{BC}$ strand is involved in the dimerization surface of TCL1, on the opposite face of the Akt binding surface, and is not thought to bind to Akt2-PHD. The affinity of related peptides, corresponding to the $\mathrm{BA}$ strands of MTCP1 and TCL1b (see Material and Methods) were also measured, but gave $\mathrm{K}_{\mathrm{D}}$ values higher than those obtained for Akt-in $\left(\mathrm{K}_{\mathrm{D}}=9 \pm 2 \mathrm{mMol}\right.$ and $68 \pm 15 \mathrm{mMol}$, respectively) (Fig. 3).

It was previously suggested that the inhibitory effect of Akt-in could be due to a loss of affinity of Akt2-PHD for phosphatidyl inositol-3,4,5-tris phosphate $\left(\mathrm{PI}(3,4,5) \mathrm{P}_{3}\right)$ [17]. $\mathrm{PI}(3,4,5) \mathrm{P}_{3}$ is the product of $\mathrm{PI} 3 \mathrm{~K}$ activation that triggers the plasma membrane translocalization of Akt, a critical step for the kinase activation. To ascertain whether the remote chemical shift perturbations observed for residues involved 

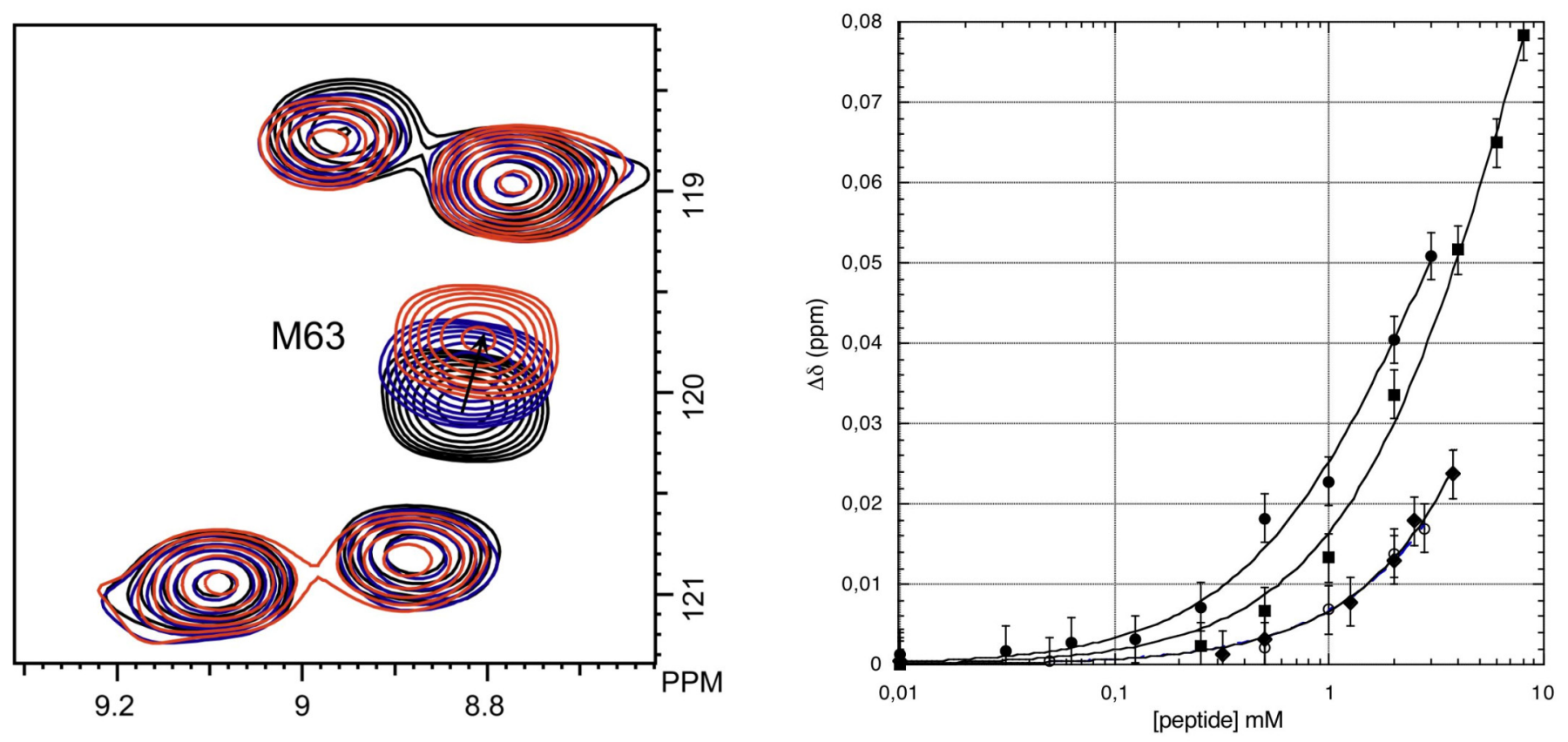

Fig. (3). Peptide titration of Akt2-PHD. (Left) Selected region of $\left[{ }^{1} \mathrm{H},{ }^{15} \mathrm{~N}\right] 2 \mathrm{D}$ HSQC spectra of ${ }^{15} \mathrm{~N}-$ labeled Akt2-PHD ([100 $\left.\mu \mathrm{M}\right]$ in 10 $\mathrm{mM}$ Tris buffer, $300 \mathrm{mM} \mathrm{NaCl}, \mathrm{pH}$ 7.4) binding to Akt-in. Spectra were collected at peptide:protein ratio roughly of 0:1 (black), 5:1 (blue), 10:1 (red). (Right) Plots of the cumulative chemical shift variations $(\Delta \delta)$ as a function of the peptide concentration. The solid curves fit to equation [1] (Material and Methods). Filled circles correspond to titration by Akt-in, open circles to titration by the control peptide ( $B C$ strand from TCL1), filled squares and filled diamonds to titration with the corresponding peptides (ßA strand) from the MTCP1 and TCL1b isoforms of TCL1.

in the phosphatidyl inositol pocket (VL1 loop) upon Akt-in binding could reflect structural perturbations responsible for a decrease in affinity for phosphatidyl Inositol phosphates, we used NMR titration to measure the $K_{D}$ of formation of the Inositol-1,3,4,5-tetrakis phosphate ( $\left.\mathrm{IP}_{4}\right)$ :Akt2-PHD complex in the presence or absence of $A k t$-in. $\mathrm{IP}_{4}$ corresponds to the water soluble polar head group of $\mathrm{PI}(3,4,5) \mathrm{P}_{3}$, and as been extensively used as a mimic of the phospholipide. Similarly, the $\mathrm{K}_{\mathrm{D}}$ of the $\mathrm{IP}_{4}$ :Akt2-PHD complex was measured in the presence of the protein TCL1. Cross-peaks corresponding to the $\delta-\mathrm{NH}_{2}$ side chain resonances of $\mathrm{N} 53$, that exhibits the largest chemical shift perturbation upon binding to $\mathrm{IP}_{4}$ [28], was used as a probe for the titrations. The side chain amino group of this residue is doubly $\mathrm{H}$-bonded to both the D3 phosphate and the D4 phosphate of IP4 in the crystal structure of Akt1-PHD bound to IP4 [51]. In the absence of any ligands (TCL1 or $A k t$-in), a $\mathrm{K}_{\mathrm{D}}$ value of $141 \pm 9 \mu \mathrm{M}$ was obtained for the complex IP4:Akt2-PHD, compatible with values from the literature [52]. In the presence of $10 \mu \mathrm{M}$

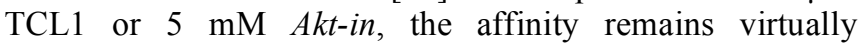
unchanged $\left(\mathrm{K}_{\mathrm{D}}=121 \pm 5 \mu \mathrm{M}\right.$ or $156 \pm 10 \mu \mathrm{M}$, respectively) (Fig. 4).

\section{Akt-in NMR Structure: Free Form and Bound to Akt2- PHD}

Regardless of the $\mathrm{pH}$ of the buffer used for solubilization, the CD spectra suggest that the peptide is largely unstructured in solution (Fig. 5), with minimum ellipticity close to $200 \mathrm{~nm}$ and no positive signal around $190 \mathrm{~nm}$. Thus, we decided to undertake the NMR analysis of $A k t$-in at $\mathrm{pH}=3$, in order to overcome classical problems due to amide proton exchange with water at high $\mathrm{pH}$ (even if further studies in the presence of Akt2-PHD were performed at neutral $\mathrm{pH}$ ). Standard proton resonance assignments were obtained via the sequential assignment strategy described by Wüthrich et al. [53], on the basis of the analysis of 2D TOCSY and 2D off-resonance ROESY (Fig. 6) recorded at $7^{\circ} \mathrm{C}$. The relatively low temperature for the study is inferred to the stability of Akt2-PHD. Consistently with CD spectroscopy, we observed very few long-range connectivity's either in the NOESY or ROESY spectra, indicating an absence of regular structure in the peptide.

Thanks to the increased sensitivity of the NMR cryoprobe, we were also able to record 2D heteronuclear correlation experiments, namely $\left[{ }^{1} \mathrm{H},{ }^{13} \mathrm{C}\right]$-HSQC, $\left[{ }^{1} \mathrm{H},{ }^{13} \mathrm{C}\right]-$ HSQC-TOCSY and $\left[{ }^{1} \mathrm{H},{ }^{15} \mathrm{~N}\right]$-HSQC, within reasonable measuring times (3 hours, 7 hours, and 12 hours, respectively). Starting from our previous proton resonance assignment, all $\mathrm{C} \alpha$ and $\mathrm{C} \beta$ and most of aliphatic carbon resonances were readily assigned using $\left[{ }^{1} \mathrm{H},{ }^{13} \mathrm{C}\right]-\mathrm{HSQC}$, $\left[{ }^{1} \mathrm{H},{ }^{13} \mathrm{C}\right]$-HSQC-TOCSY recorded at $7^{\circ} \mathrm{C}$. For the assignment of amide nitrogen resonances, we recorded $\left[{ }^{1} \mathrm{H},{ }^{15} \mathrm{~N}\right]-\mathrm{HSQC}$ spectra at two temperatures $\left(7^{\circ} \mathrm{C}\right.$ and $\left.17^{\circ} \mathrm{C}\right)$ in order to overcome proton resonance overlapping. The complete resonance assignment is presented in Table $\mathbf{1}$.

With $\mathrm{H} \alpha, \mathrm{HN}, \mathrm{N}, \mathrm{C} \alpha$ and $\mathrm{C} \beta$ resonance assignment available, we were able to use the TALOS software in order to define $\phi$ and $\psi$ dihedral angles along the peptide sequence. Again, this analysis indicates that the peptide is in a randomcoil conformation.

Finally, we used the transferred nOe technique [54] to define the structure of Akt-in when bound to Akt2-PHD. Since this 15 residue-long peptide exhibits negative nOe's 

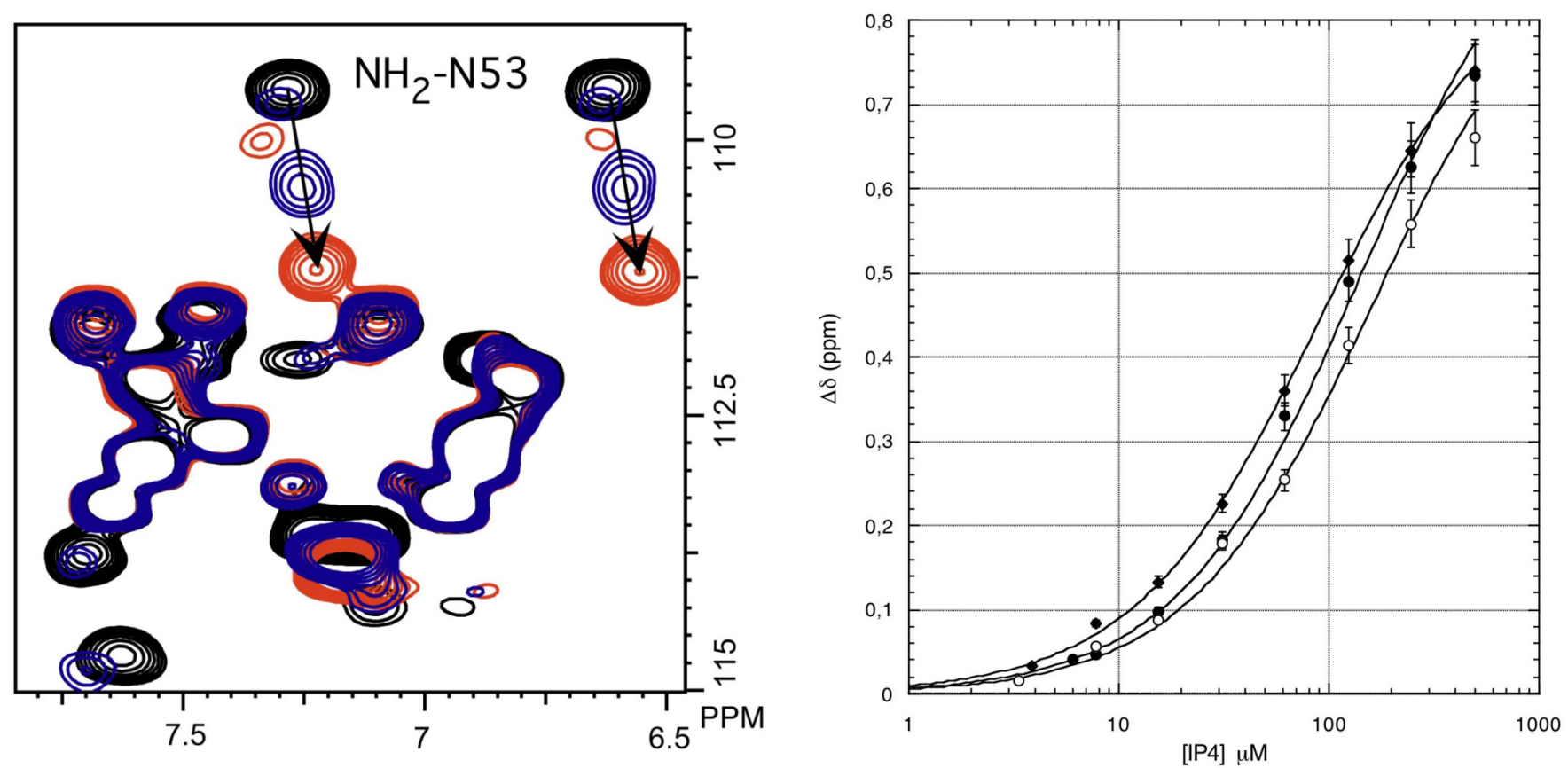

Fig. (4). IP4 titration of Akt2-PHD. (Left) Selected region of $\left[{ }^{1} \mathrm{H},{ }^{15} \mathrm{~N}\right] 2 \mathrm{D}$ HSQC spectra of ${ }^{15} \mathrm{~N}$-labeled Akt2-PHD (same conditions as in Fig. (3), except that no $\mathrm{NaCl}$ was present in the buffer) binding to IP4. Spectra were collected at IP4:protein ratio roughly of 0:1 (black), 0.1:1 (blue), 1:1 (red). (Right) Plots of the cumulative chemical shift variations $(\Delta \delta)$ as a function of IP4 concentration. The solid curves fit to equation [1] (Material and Methods). Filled circles correspond to IP4 titration of Akt2-PHD alone in solution, open circles to IP4 titration of Akt2-PHD in the presence of $5 \mathrm{mM} \mathrm{Akt-in}$, filled diamond to IP4 titration of Akt2-PHD in the presence of $5 \mu \mathrm{M}$ TCL1.

when free in solution on a $2 \mathrm{D}$ NOESY recorded at $7^{\circ} \mathrm{C}$, we added an isotopic filter to the conventional 2D NOESY experiment [36]. When using ${ }^{15} \mathrm{~N}$-labeled Akt2-PHD, this allowed us to suppress any nOe's arising from amide proton belonging to the protein and to observe only nOe's arising from the peptide resonances in the amide region of the spectrum. Note that we were not able to adjust the temperature in order to enhance the correlation time and to suppress nOe's from the peptide, since Akt2-PHD is unstable beyond $10^{\circ} \mathrm{C}$. Whatever the mixing time $(100 \mathrm{~ms}$ to $500 \mathrm{~ms}$ ) or the protein:peptide ratio (1/100 to $1 / 10)$, we did not observe any additional nOe's in the amide region of the NOESY spectra recorded in the presence of Akt2-PHD, suggesting that the peptide remains unstructured in the bound state.

Despite the mass of evidences suggesting that Akt-in exists in a random-coil conformation, we used the NMR parameters to calculate a model for its "structure" using CYANA. As a result, we obtain a bundle of 20 structures (Fig. 6), more or less in an extended conformation that should represent the accessible conformational space for the peptide atoms. The statistics calculated on these 20 models are presented in Table 2 . Rather than representing a "realistic" 3D model, these conformations were used as "possible" starting structures in HADDOCK calculations.

Areas within Akt2-PHD that undergo significant chemical shifts on average $>2 \sigma$ upon peptide binding were used as a basis for determining "active" interface residues in the Aktin:Akt2-PHD complex. On this basis, 11 residues were selected: G16, Y18, V57, A58, L62, M63, K64, E66, V74, F88 and M100. Among these residues, V57, V74 and F88 were discarded since they are deeply buried in the hydrophobic core of the $\beta$-sandwich. G16 and Y18, located on the phosphatidyl inositol pocket, on the opposite face of the molecule with respect to the remaining residues, were also rejected. Indeed, titration experiments have shown that Akt2-PHD affinity for IP4 is unaffected by the presence of Aktin: the peptide is thus unlikely to bind on this site. Finally, we retained 6 active residues for the protein, and 4 active residues for the peptide: L9, W10, W12 and F15, responsible for a significant decrease in affinity when exchanged by an alanine residue. For each modeling procedure, a series of ambiguous interaction restraints were generated between the active residues of the two molecules. The docking procedure consisted of three stages: rigid body energy minimization, semi-flexible refinement with simulated annealing, and explicit water refinement. The protocol resulted in 200 refined protein:peptide complexes, which were subsequently clustered as a function of their backbone RMSD from the lowest energy structure. Each modeling protocol resulted in two main clusters $(40 \%$ and $30 \%$ of the structures), arising from two possible orientations of the peptide. For each peptide studied the lower energy (best) solution cluster maps to the same region of Akt2-PHD, consisting of an hydrophobic crevice between the 35 strand of the $\beta$-sandwich and the C-terminal helix (Fig. 7). In the two clusters, the hydrophobic C-terminal residues of the peptide (L9, W10, W12 and F15) adopt an extended conformation and are buried in the crevice, whereas the Nterminal end points toward two opposite directions, corresponding roughly to the $\mathrm{N}$-terminal or the C-terminal of the PH domain helix. Whatever the cluster, the N-terminal end of Akt-in explores a large conformational space without displaying any preferential conformation, consistent with 


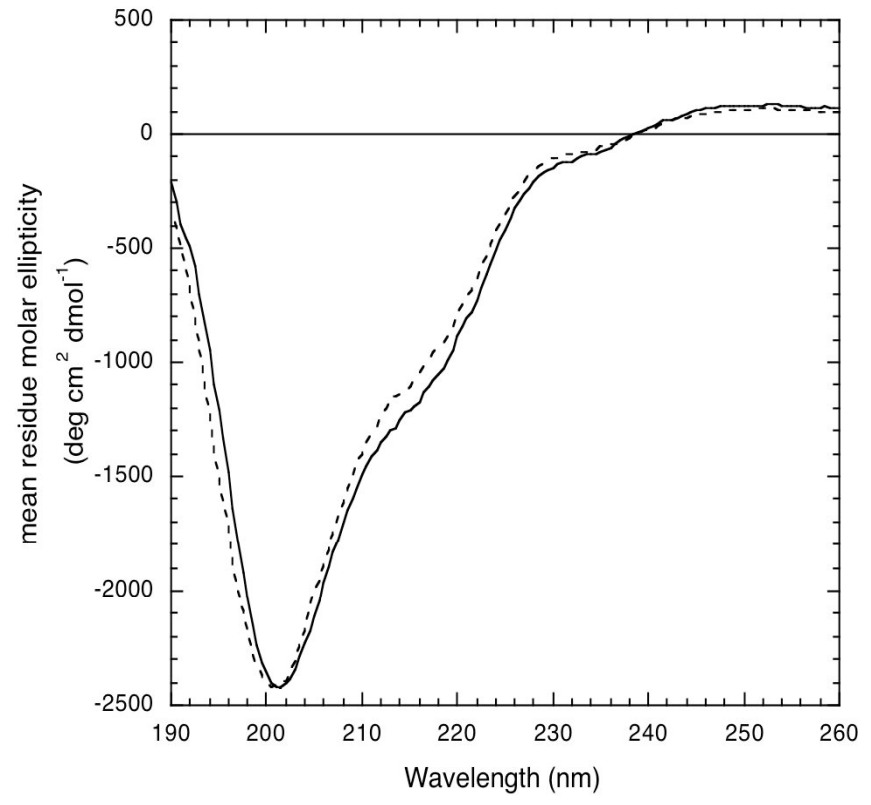

Fig. (5). Far UV-CD spectra of $A k t$-in. CD spectra of $A k t$-in were recorded either at $\mathrm{pH} 3$ (dotted line) in water, or at $\mathrm{pH} 7.4$ (plain line) in $10 \mathrm{mM}$ Tris buffer, $300 \mathrm{mM} \mathrm{NaCl}$.

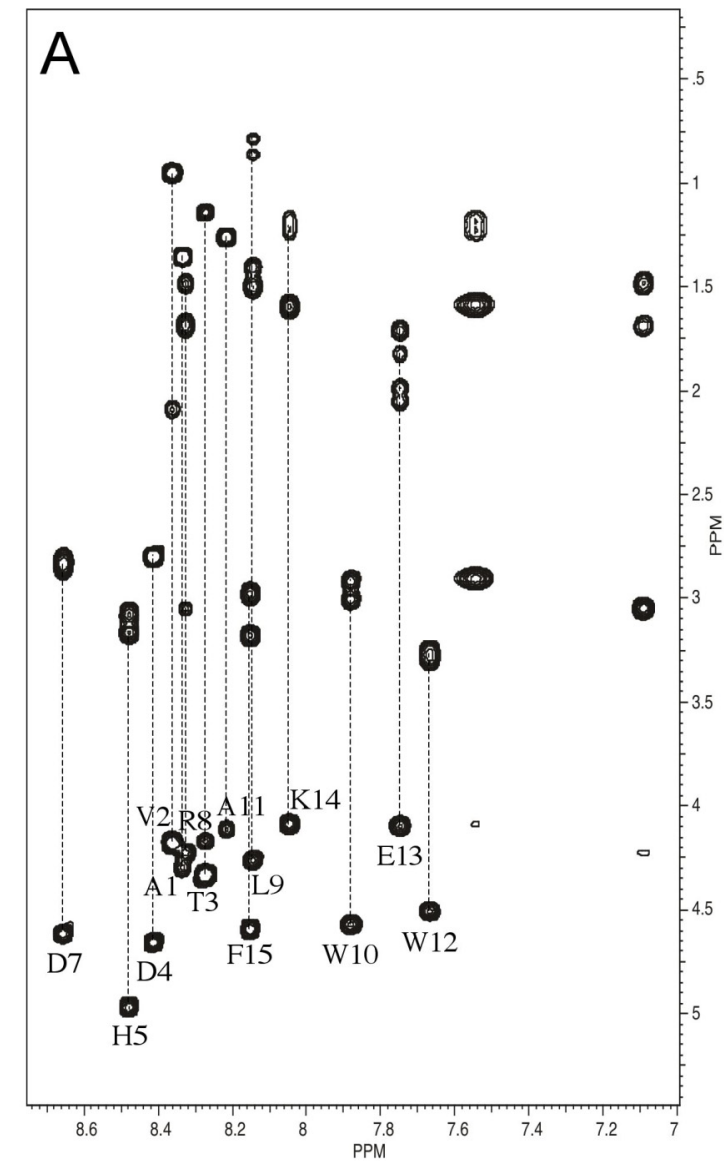

what observed in the transfered nOe's experiments. In the two clusters, the two tryptophan residues adopt a similar central position, exhibiting numerous hydrophobic contacts with surrounding side-chains centered around M63 on the 35 strand and M100 on the $\alpha$-helix (Fig. 7). In cluster 1, the residue F15 is deeply buried in an hydrophobic pocket consisting of residues I103, V106, A107, K111 on the helix and A58, C60 on the 35 strand, whereas it remains more solvent exposed in cluster 2 . In the two clusters, L9 shows only few contacts with the protein, that involve mainly the $\mathrm{N}$-terminal R8 residue. Potential hydrogen bonds can also be identified that involve mainly amide polar groups on the peptide backbone or the indolic nitrogen of the tryptophane side-chains.

\section{DISCUSSION}

The inhibitor $A k t$-in has been rationally designed from the precise knowledge of the interacting surfaces deduced from the 3D model of the Akt2-PHD:TCL1 complex previously obtained through NMR and SAXS analysis [27]. The binding surface of TCL1 on Akt2-PHD, as revealed by NMR and site-specific mutations of TCL1 $[55,56]$, involves mainly residues located in the $\beta \mathrm{A}, \beta \mathrm{B}, \beta \mathrm{E}$ and $\beta \mathrm{F}$ strands of the $\beta$-barrel structure, that form a continuous surface of
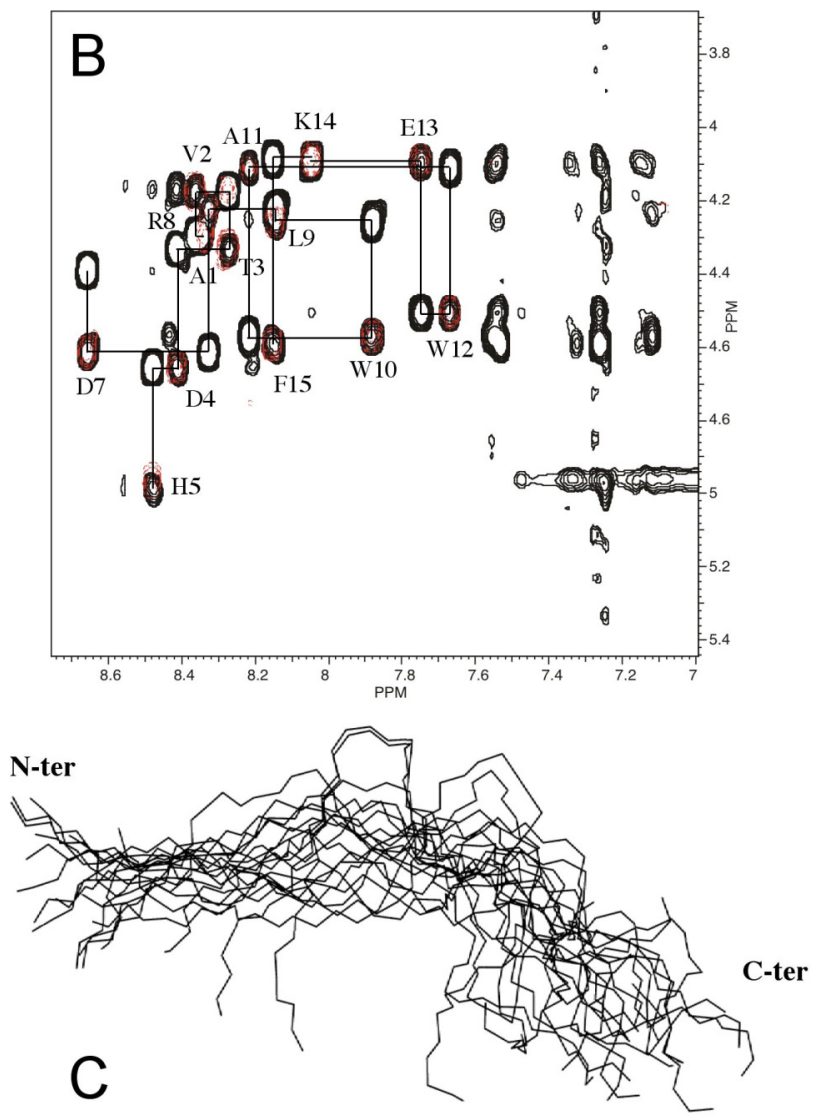

Fig. (6). $A k t$-in ${ }^{1} \mathrm{H}$ NMR study and $3 \mathrm{D}$ solution structure. All spectra were recorded on a $2 \mathrm{mM}$ sample of $A k t$-in dissolved in water at pH 3 and $10^{\circ} \mathrm{C}$. Cross-peaks corresponding to $\mathrm{NH}-\mathrm{H} \alpha$ scalar correlations are labeled with the one letter code of amino acids and numbering of the peptide. (A) Amide region of the 2D TOCSY spectrum. The vertical dotted lines indicate the intra-spin system scalar connectivities. (B) Walk on the sequential $d_{\mathrm{NH}-\mathrm{H}_{\alpha}}$ connectivities (horizontal and vertical line) in an off-resonance 2D ROESY (black lines). For the sake of clarity, the same region of the 2D TOCSY spectrum has been superimposed in red: the red cross-peaks corresponds to NH-H $\alpha$ intra-residue connectivities. (C) Bundle of 20 best CYANA structures. The N-and C-terminal ends of the peptide are indicated. 
Table 1. Akt-in ${ }^{1} \mathrm{H},{ }^{13} \mathrm{C}$ and ${ }^{15} \mathrm{~N}$ Resonance Assignment at $10^{\circ} \mathrm{C}, \mathrm{pH}$ 3. Proton Chemical Shifts are given into Brackets

\begin{tabular}{|c|c|c|c|l|}
\hline Residue & $\mathbf{N}(\mathbf{H N})(\mathbf{p p m})$ & $\mathbf{C}^{\alpha}\left(\mathbf{H}^{\alpha}\right)(\mathbf{p p m})$ & $\mathbf{C}^{\beta}\left(\mathbf{H}^{\beta}\right)(\mathbf{p p m})$ & \multicolumn{1}{|c|}{$\mathbf{C}(\mathbf{H})$ Others $(\mathbf{p p m})$} \\
\hline \hline A1 & $130.1(8.341)$ & $52.53(4.291)$ & $19.14(1.360)$ & \\
\hline V2 & $120.0(8.370)$ & $62.39(4.177)$ & $32.79(2.092)$ & $\mathrm{C}^{\gamma 1}, 21.18(0.965) ; \mathrm{C}^{\gamma}, 21.18(0.933)$ \\
\hline T3 & $117.7(8.281)$ & $61.55(4.334)$ & $69.75(4.165)$ & $\mathrm{C}^{\gamma}, 21.33(1.145)$ \\
\hline D4 & $121.3(8.421)$ & $52.78(4.666)$ & $38.19(2.786,2.824)$ & \\
\hline H5 & $119.0(8.485)$ & $53.31(4.971)$ & $28.55(3.081,3.164)$ & $\mathrm{C}^{\delta 2},(7.260) ; \mathrm{C}^{\varepsilon 1},(8.559)$ \\
\hline P6 & & $63.45(4.391)$ & $32.22(1.891,2.265)$ & $\mathrm{C}^{\gamma}, 27.33(1.961,1.986) ; \mathrm{C}^{\delta}, 50.74(3.621,3.641)$ \\
\hline D7 & $119.6(8.664)$ & $53.00(4.626)$ & $37.95(2.809,2.875)$ & \\
\hline R8 & $121.8(8.334)$ & $56.21(4.224)$ & $43.20(1.667,1.698)$ & $\mathrm{C}^{\gamma}, 30.59(1.479,.) ; \mathrm{C}^{\delta}, 26.87(3.051,.) ; \mathrm{N}, 89.252(7.100)$ \\
\hline L9 & $122.6(8.154)$ & $55.28(4.260)$ & $42.12(1.493,1.388)$ & $\mathrm{C}^{\gamma}, 26.98(1.460) ; \mathrm{C}^{\delta 1}, 24.84(0.864) ; \mathrm{C}^{\delta 2}, 23.39(0.792)$ \\
\hline W10 & $121.0(7.886)$ & $56.80(4.576)$ & $29.71(2.922,3.009)$ & $\mathrm{C}^{\delta 1},(7.130) ; \mathrm{C}^{\zeta 2},(7.359) ; \mathrm{N}^{\varepsilon 1}, 129.2(10.14)$ \\
\hline A11 & $124.9(8.222)$ & $53.27(4.121)$ & $18.86(1.262)$ & \\
\hline W12 & $117.8(7.675)$ & $57.35(4.514)$ & $28.99(3.256,3.295)$ & $\mathrm{C}^{\delta 1},(7.272) ; \mathrm{C}^{\zeta 2},(7.483) ; \mathrm{N}^{\varepsilon 1}, 129.9(10.12)$ \\
\hline E13 & $121.5(7.754)$ & $55.81(4.101)$ & $28.78(1.716,1.830)$ & $\mathrm{C}^{\gamma}, 32.56(1.989,2.055)$ \\
\hline K14 & $121.8(8.053)$ & $56.39(4.088)$ & $32.82(1.614,)$. & $\mathrm{C}^{\gamma}, 24.63(1.180,1.236) ; \mathrm{C}^{\delta}, 29.01(1.584) ; \mathrm{C}^{\varepsilon}, 41.87(2.915,2.893) ; \mathrm{N}^{\zeta}$, \\
\hline F15 & $121.3(8.158)$ & $57.29(4.601)$ & $39.72(3.188,2.982)$ & $\mathrm{C}^{\delta},(7.271) ; \mathrm{C}^{\gamma},(7.329) ; \mathrm{C}^{\varepsilon},()$. \\
\hline
\end{tabular}

about $788 \AA^{2}$ which is highly conserved among TCL1 family members. The binding site of TCL1 on Akt2-PHD consists in $\mathrm{a} \approx 830 \AA^{2}$ surface comprising residues located in the $\mathrm{C}$ terminal $\alpha$-helix, as well as residues located in the $\beta 4$ and $\beta 5$ strands on one face of the $\beta$-sandwich. In the present study, chemical shift mapping experiments confirm that the binding site of the peptide inhibitor $A k t$-in - that corresponds roughly to the BA strand of TCL1 - on Akt2-PHD spans the TCL1 binding surface. Nevertheless, a closer look at the HADDOCK peptide-protein complex models reveals substantial differences in the mode of interaction. For models gathered in cluster 2, the L9-F15 C-terminal peptide segment adopts a similar orientation as the corresponding peptide segment (L18-F24) in the complex TCL1:Akt2PHD. In these models, W10 (corresponding to W19 in TCL1) exhibits few interactions with surrounding hydrophobic side chains on Akt2-PHD (A58, E59, A107), and its indole nitrogen is $\mathrm{H}$-bonded to $\mathrm{C} 60$. The side chain of $\mathrm{W} 12$ (corresponding to W21 in TCL1) gives rise to an important interaction network involving hydrophobic side chains on the PH domain (L62, M63, F73, M100, I103), and its backbone carbonyl is H-bonded to K64. Interestingly, in the complex TCL1:Akt2-PHD, W19 occupies a similar position as $\mathrm{W} 12$ in the cluster 2 models, establishing numerous inter-molecular hydrophobic contacts with the $\mathrm{C}$ terminal helix of the PH domain (I103, Q104, A107). On the other hand, W21 exhibits only intramolecular interactions with side chains located on the loop connecting the $2 \beta$ meanders that forms the TCL1 $\beta$-barrel [21].

In cluster 1 models, the peptide has the reverse orientation with regard to the TCL1 BA strand in the TCL1:Akt2-PHD complex, and most of the hydrophobic stabilizing intermolecular interactions involve residue F15 (F24 in TCL1). Nevertheless, the contribution of W12
Table 2. Statistics Obtained form 20 CYANA Structures of the Peptide $A k t$-in

\begin{tabular}{|ll|}
\hline Number of NOE distance restraints & \\
intraresidue & 4 \\
sequential & 43 \\
lmedium-range $(\leq 4)$ & 4 \\
total & 51 \\
\hline Number of dihedral angle constraints $(\Phi$ and $\Psi)$ & 2 \\
\hline Target function of CYANA $\left(\AA^{2}\right)$ & $0.02 \pm 0.00$ \\
\hline Ramachandran plot for residues 1 to $15(\%)$ & \\
most favoured region & 72.3 \\
additionally allowed region & 23.1 \\
generously allowed region & 4.6 \\
disallowed region & 0.0 \\
\hline Average $r . m . s$. deviation from mean structure for residues $1-15(\AA)$ \\
backbone atoms & $4.52 \pm 1.67$ \\
heavy atoms & $6.30 \pm 1.40$ \\
\hline
\end{tabular}

cannot be neglected: its aromatic side chain establishes hydrophobic contacts with L62 and K64 on the 35 strand of Akt2 $\mathrm{PH}$ domain, while its indole nitrogen is $\mathrm{H}$-bonded to M100 on the C-terminal helix. The side chain of W10 is more solvent exposed and shows only hydrophobic contacts with M63 and is H-bonded to L62 (indole nitrogen) and to K64 (backbone carbonyl). In the 3D structure of TCL1, F24 is located in the turn connecting $\beta 1$ and $\beta 2$ strands with its side chain looking at the inside of the barrel and establishing 

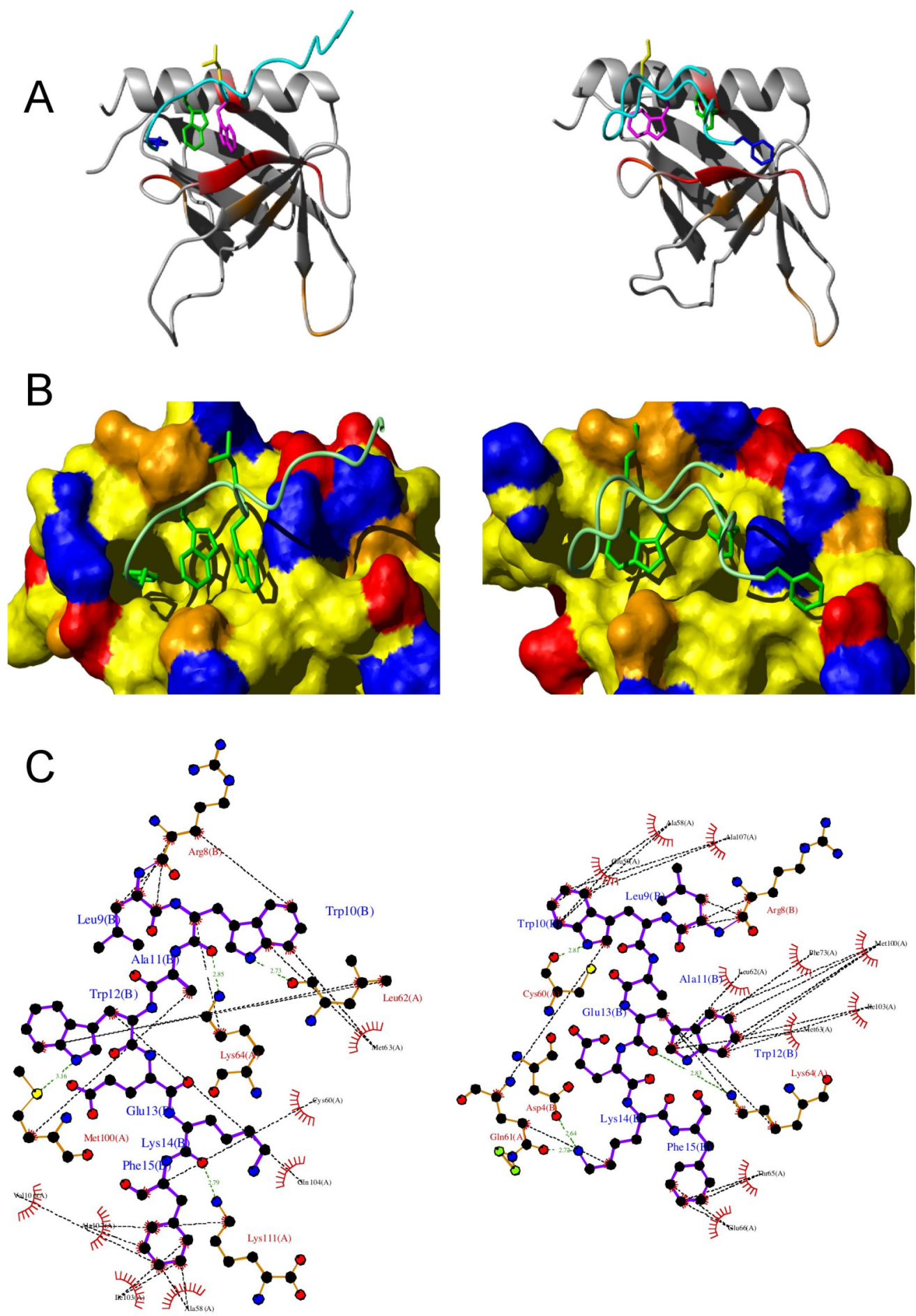

Fig. (7). NMR-derived models of the Akt-in:Akt2-PHD complex using the HADDOCK program. The left panels correspond to cluster 1 (40 $\%$ of the resulting structures), the right panels to cluster 2 (30\% of the resulting structures). (A) Ribbon representation of the complex. Colored residues in the protein indicate the footprint in the presence of $A k t$-in determined by the NMR mapping (same code as in Fig. 1). The peptide backbone is colored in cyan; only the side chains of the active residues are reported (L9: yellow sticks; W10: pink sticks; W12: green sticks; F15: dark blue sticks). (B) Zoom in the binding interface: the protein residues are displayed as Van der Waals surface (yellow: hydrophobic residues; orange: polar residues; red: acidic residues; blue: basic residues), the peptide backbone as a light green solid ribbon. Again, only the "active" hydrophobic side chains of the inhibitor are displayed with green sticks. (C) Schematic representation of the atomic contacts at the interface between Akt-in and Akt2-PHD obtained with LigPlot [62]. The peptide (Molecule B) residues are in ball-and-stick representation and labelled in blue. The protein (Molecule (A) residues that bring atoms H-bonded with the ligand are also displayed with the ball-and-stick representation and labelled in red. H-bonds are represented as green dotted lines. Protein residues that exhibits hydrophobic contacts with the ligand are labeled in black and represented as small red "brushes". The hydrophobic network is displayed as black dotted lines. 
only intramolecular interactions. The residue L18 is deeply buried in the hydrophobic barrel of TCL1 and contributes to the stability of the hydrophobic core, whereas Ala-scan experiments have shown that the corresponding residue in Akt-in (L9) contributes significantly to the interaction with the PH domain. Similarly, replacing D7 (D16 in TCL1) with an alanine residue does not affect the peptide affinity, whereas site-directed mutations on TCL1 have previously shown that D16 has a pivotal role for the interaction with Akt2-PHD [38]. In summary, Akt-in binds a surface on Akt2 $\mathrm{PH}$ domain that indeed encompasses the binding site of TCL1. As for the BA-strand of TCL1, it adopts a similar extended conformation (at least for the C-terminal "active" residues) when bound to Akt2-PHD. But, the details of the interaction revealed by the present study are clearly different between the peptide-protein and protein-protein complexes. Note that, since the mode of interaction between Akt-in and Akt2-PHD should be markedly different than the one between TCL1 and Akt2-PHD, it becomes difficult to assess which models - cluster 1 or 2 - correspond to the "right" solution, only on the basis of "rational" design.

In addition to allowing an accurate modeling of the peptide: $\mathrm{PH}$ domain complex, Ala-scanning points out the importance of the tryptophan residues for the peptide affinity. In the two clusters, the tryptophan residues occupy a central position in the interaction network, and appear as mandatory residues for affinity. Indeed, the control peptide corresponding to the $\mathrm{BC}$ strand of TCL1, that lacks the two tryptophan residues at position 10 and 12 (Akt-in numbering), has almost no affinity for the $\mathrm{PH}$ domain. Interestingly and consistent with the Ala-scan experiment, the peptides corresponding to the $B A$ strand of either the variant TCL1b or MTCP1, that lacks W12 (Akt-in numbering), show a significantly decreased affinity with regard to Akt-in. Moreover, MTCP1 has been shown to exhibit a 100-fold lower affinity for Akt2-PHD [27] when compared to TCL1 (TCL1b affinity has never been measured until now): if not completely related, it seems that the interaction between $A k t$-in and Akt2-PHD might retain some atomic features of the interaction between TCL1 and Akt2PHD.

Intriguingly, we observed a very significant discrepancy between the peptide affinities measured in the present study and reported previously [17]. The kinetic study of Akt-in interaction with Akt2-PHD was previously performed by Spot Matrix SPR technology: a dissociation constant of about $20 \mu \mathrm{M}$ was reported, an about 100-fold value lower than the $\mathrm{k}_{\mathrm{D}}$ measured in the present study using NMR titration. Note that the $\mathrm{k}_{\mathrm{D}}$ values measured either by SPR, fluorescence polarization or NMR titration for the TCL1:Akt2-PHD complex were in perfect agreements (about $5 \mu \mathrm{M}$, whatever the technique used). A possible explanation might be a non specific interaction of the peptide with the matrix used in the SPR experiments that will give erroneous results. On the other hand, a millimolar affinity is unlikely to explain the cellular or in vivo effects observed with Akt-in treatment, such as specific inhibition of Akt phosphorylation and membrane translocation, in vitro inhibition of Aktdependent cellular proliferation, stabilization of mitochondrial permeability transition, anti-apoptosis, or tumor cell growth inhibition [17].
A possible solution to this disconcerting paradox might reside in the molecular mode of action of Akt-in. In a previous report [17], we postulated that the binding of $A k t$-in to Akt2-PHD inhibits the association of the kinase to the plasma membrane PtdIns. Indeed, NMR mapping study suggest that Akt-in binding induces remote conformational changes at the locus (Variable Loop 1) involved in the PtdIns binding (Fig. 1A) that could disturb the interaction with the lipid. In the present study, we show that if such remote perturbations on the VL1 loop do exist, they do not affect the PH domain affinity for IP4, the soluble polar head-group of PtdIns. Indeed, $\mathrm{K}_{\mathrm{D}}$ values measured for the complex IP4:Akt2-PHD alone in solution or in the presence of $A k t$-in is virtually identical. Another possible mechanism of action for Akt-in might be postulated from the observation of the models obtained for the peptide-protein complex. Whatever the cluster under consideration, the binding to Akt2-PHD involves only the C-terminal hydrophobic segment of $A k t$-in, the rest of the peptide (segment A1-R8) remaining "free" in solution. This segment might establish interactions with the neighbouring Akt kinase domain in the entire molecule. The kinase domain, bearing the catalytic site, is separated from the pleckstrin homology domain by a 39 -amino acid flexible "inter-domain" region. In its cytoplasmic unphosphorylated unactive form, the $\mathrm{PH}$ domain is thought to be folded over the kinase domain. In this closed conformation, Akt cannot be phosphorylated by PDK1: the PH domain occludes the activation loop, including the critical T309 residue, and block access to the upstream activating kinase. When the $\mathrm{PH}$ domain binds to the membrane, it umasks the critical Ser/Thr residues on the kinase domain: Akt activation can proceed [57]. Thus, several small molecules that can retain Akt in its "closed" unactive cytoplasmic conformation, have been proposed as "allosteric" Akt inhibitors [58]. We think that Akt-in might have a similar mode of action, bridging the two Akt domains through the simultaneous binding of the $\mathrm{C}$ terminal L9-F15 hydrophobic segment to the PH domain (as described in the present study) and of $\mathrm{N}$-terminal residues to the kinase domain (to be investigated!). By this way, Akt-in should be considered as a peptide harbouring two pharmacophores: a first "fragment" binds to the PH domain, a second "fragment" to the kinase domain. Considering the simple rules elaborated in Fesik group $[59,60]$, the $K_{D}$ of the entire peptide should be roughly equal to the product of the $\mathrm{k}_{\mathrm{D}}$ of the two fragments. If we assume a similar (weak) affinity between the N-terminal "fragment" and the catalytic domain than the one measured in the present study between the C-terminal "fragment" and the PH domain, we should end with a micromolar affinity between $A k t$-in and the entire Akt molecule. And a micromolar affinity should be already compatible with most of the cellular effects reported for Aktin. Of course, this assumption must be now verified. But, due to the size of the full-length Akt molecule, others techniques than NMR ones should be adressed to reach this goal. It is noteworthy that, very recently, Huang and Kim [61] have used chemical cross-linking and mass spectroscopy to probe Akt-inhibitor interactions. They found that whether the binding of Akt to an PtdIns analog inhibitors caused the open interdomain conformation where the $\mathrm{PH}$ domain moved away from the kinase domain, the interdomain conformation remained unchanged after incubating with Akt-in. Using additional data from interaction with unilamellar vesicles, 
they conclude that $A k t$-in impaired particularly the opening of the PH domain for exposing T308 for phosphorylation at the plasma membrane. These results strongly support our present conclusions.

\section{CONCLUSION}

Tridimensional models have been obtained for the complex Akt-in: Akt2-PHD through HADDOCK calculation based on NMR chemical shift mapping of the protein and peptide Ala-scanning. In all the models, a C-terminal hydrophobic peptide segment binds a surface on Akt2-PHD that encompasses the TCL1 binding site. Nevertheless, the mode of interaction between $A k t$-in and the corresponding BA strand in TCL1 is markedly different, underlying a probably different mode of action. NMR titration experiments revealed that the affinity between Akt-in and Akt2-PHD is very weak and incompatible with the cellular and in vivo effects observed after Akt-in treatment. This prompted us to propose a new mechanism of action for the peptide: Akt-in might bridge the $\mathrm{PH}$ domain and the kinase domain of Akt, maintaining the kinase in a folded unactive conformation. Such a model would conciliate the weak affinity between Akt-in and Akt2-PHD measured in the present study, and the in vitro and in vivo biological effects previously reported.

\section{ACKNOWLEDGMENT}

The authors are grateful to the "Association pour la Recherche sur le Cancer" for their support. V. Ropars was granted by the "Ligue Nationale contre le Cancer".

\section{ABBREVIATIONS}

$$
\begin{array}{ll}
\text { DSS }= & \text { 2,2-Dimethyl-2-silapentane-5-sulfonate sodium } \\
& \text { salt } \\
\text { HSQC = } & \text { Heteronuclear Single Quantum Correlation } \\
\text { IP4 }= & \text { Inositol-1,3,4,5-tetrakis phosphate } \\
\text { PHD = } & \text { Pleckstrin homology domain } \\
\text { PI }= & \text { Phosphatidylinositide PKB, Proteine Kinase B } \\
& \text { PtdIns, Phosphatidylinositol } \\
\text { T-PLL = } & \text { T-Cell Prolymphocytic Leukemia }
\end{array}
$$

\section{REFERENCES}

[1] Chen WS, Xu PZ, Gottlob K, Chen ML, Sokol K, et al. Growth retardation and increased apoptosis in mice with homozygous disruption of the akt1 gene. Genes Dev 2001; 15: 2203-8.

[2] Cho $\mathrm{H}, \mathrm{Mu} \mathrm{J}, \mathrm{Kim} \mathrm{JK}$, et al. Insulin resistance and a diabetes mellituslike syndrome in mice lacking the protein kinase Akt2 (PKB beta). Science 2001; 292: 1728-31.

[3] Manning BD, Cantley LC. Akt/PKB signaling: navigating downstream. Cell 2007; 129: 1261-74.

[4] Sales EM, Sale GJ. Protein kinase B: signalling roles and therapeutic targeting. Cell Mol Life Sci 2008; 65: 113-27.

[5] Chan TO, Rittenhouse SE, Tsichlis PN. AKT/PKB and other D3 phosphoinositideregulated kinases: kinase activation by phosphoinositide- dependent phosphorylation. Annu Rev Biochem 1999; 68: 965-1014.

[6] Coffer PJ, Jin J, Woodgett JR. Protein kinase B (c-Akt): a multifunctional mediator of phosphatidylinositol 3-kinase activation. Biochem J 1998; 335: 1-13.

[7] Fruman DA, Meyers RE, Cantley LC. phosphoinositide kinases. Annu Rev Biochem 1998; 67: 481-507.

[8] Vanhaesebroeck B, Alessi DR. The PI3K-PDK1 connection: more than just a road to PKB. Biochem J 2000; 346: 561-76.
[9] Andjelkovic M, Alessi DR, Meier R, et al. Role of translocation in the activation and function of protein kinase B J Biol Chem 1997; 272: 31515-24.

[10] Brodbeck D, Cron P, Hemmings BA. A human protein kinase Bg with regulatory phosphorylation sites in the activation loop and in the C-terminal hydrophobic domain. J Biol Chem 1999; 274: 91336.

[11] Stephens L, Anderson K, Stokoe D, et al. Protein kinase B kinases that mediate phosphatidylinositol 3,4,5-trisphosphate-dependent activation of protein kinase B. Science 1998; 279: 710-4.

[12] Alessi DR, James SR, et al. Characterization of a 3phosphoinositide-dependent protein kinase which phosphorylates and activates protein kinase Ba. Curr Biol 1997; 7: 261-9.

[13] Hill MM, Andjelkovic M, Brazil DP, et al. Insulinstimulated protein kinase B phosphorylation on Ser-473 is independent of its activity and occurs through a staurosporineinsensitive kinase. J Biol Chem 2001; 276: 25643- 6 .

[14] Datta SR, Brunet A, Greenberg ME. Cellular survival: a play in three Akts. Genes Deve 1999; 13: 2905-7.

[15] Vivanco I, Sawyers CL. The phosphatidylinositol 3-Kinase Akt pathway in human cancer. Nat Rev Cancer 2002; 2: 489-501.

[16] Luo J, Manning BD, Cantley LC. Targeting the PI3K-Akt pathway in human cancer:rationale and promise. Cancer Cell 2003; 4: 25762 .

[17] Hiromura M, Okada F, Obata T, et al. Inhibition of Akt kinase activity by a peptide spanning the $B A$ strand of the protooncogeneTCL1. J Biol Chem 2004; 279: 53407-18.

[18] Virgilio L, Narducci MG, Isobe $\mathrm{M}$, et al. Identification of the TCL1 gene involved in T-cell malignancies. Proc Natl Acad Sci USA 1994; 91: 12530- 4.

[19] Stern MH, Soulier J, Rosenzwajg M, et al. MTCP-1: a novel gene on the human chromosome $\mathrm{Xq} 28$ translocated to the $\mathrm{T}$ cell receptor alpha/delta locus in mature T cell proliferations. Oncogene 1993; 8: 2475-83.

[20] Pekarsky Y, Hallas C, Isobe M, Russo G, Croce CM. Abnormalities at $14 \mathrm{q} 32.1$ in Tcell malignancies involve two oncogenes. Proc Natl Acad Sci USA 1999; 96: 2949-51.

[21] Guignard L, Padilla A, Mispelter J, et al. Backbone dynamics and solution structure refinement of the $15 \mathrm{~N}$-labeled human oncogenic protein p13MTCP1 comparison with the X-ray data. J Biomol NMR 2000; 17: 215-30.

[22] Yang YS, Guignard L, Padilla A, et al. Solution structure of the recombinant human oncoprotein p13MTCP1. J Biomol NMR 1998; 11:339-56.

[23] Hallas C, Pekarsky Y, Itoyama T, et al. Genomic analysis of human and mouse TCL1 loci reveals a complex of tightly clustered genes. Proc Natl Acad Sci USA 1999; 96: 14418-23.

[24] Hoh F, Yang YS, Guignard L, et al. Crystal structure of p14TCL1, an oncogene product involved in T-cell prolymphocytic leukemia, reveals a novel beta-barrel topology. Structure 1998; 6: 147-55.

[25] Laine J, Kunstle G, Obata T, Sha M, Noguchi M. The protooncogene TCL1 is an Akt kinase coactivator. Mol Cell 2000; 6: 395- 407.

[26] Pekarsky Y, Koval A, Hallas C, et al. Tcl1 enhances Akt kinase activity and mediates its nuclear translocation. Proc Natl Acad Sci USA 2000; 97: 3028-33.

[27] Auguin D, Barthe P, Royer C, et al. Structural basis for the coactivation of protein kinase B by T-cell leukemia-1 (TCL1)family proto-oncoproteins. J Biol Chem 2004; 279: 35890-902.

[28] Auguin D, Barthe P, Auge-Senegas MT, Stern MH, Noguchi M, Roumestand C. Solution structure and backbone dynamics of the pleckstrin homology domain of the human protein kinase B (PKB/Akt). interaction with inositol phosphates. J Biomol NMR 2004; 28: 137-55.

[29] Noguchi M, Ropars V, Roumestand C, Suizu F. Protooncogene TCL1: more than just a co-activator for Akt. FASEB J 2007; 2: 2273-84.

[30] Teitell MA. The TCL1 family of oncoproteins: co-activators of transformation. Nat Rev Cancer 2005; 5: 640-8.

[31] Marion D, Ikura M, Tschudin R, Bax A. Rapid recording of 2D NMR data without phase cycling. Application to the study of hydrogen exchange in proteins. J Magn Reson 1989; 85: 393-99.

[32] Jeener J, Meier BH, Bachman P, Ernst RR. Investigation of exchange processes by two-dimensional NMR spectroscopy. J Chem Phys 1979; 71: 4546-53. 
[33] Kumar A, Ernst RR, Wüthrich KA. Two-dimensional nuclear Overhauser Enhancement (2D NOE) experiment for the elucidation of complete proton-proton crossrelaxation networks in biological macromolecules. Biochem Biophys Res Commun 1980; 95: 1-6.

[34] Otting G, Wüthrich K. Heteronuclear filters in two-dimensional $[1 \mathrm{H}, 1 \mathrm{H}]-\mathrm{NMR}$ spectroscopy: combined use with isotope labelling for studies of macromolecular conformation and intermolecular interactions. Q Rev Biophy 1990; 23: 39-96.

[35] Berthault P, Birlirakis N, Rubinstenn G, Sinaÿ P, Desvaux H. Solution structure of a Lewis(x) analogue by off-resonance $1 \mathrm{H}$ NMR spectroscopy without use of an internal distance reference. J Biomol NMR 1996; 8: 23-35.

[36] Braunschweiler L, Ernst RR. Coherence transfer by isotropic mixing: application to proton correlation spectroscopy. J Magn Reson 1983; 53: 521-8.

[37] Davis DG, Bax A. Assignment of complex 1H NMR spectra with two-dimensional homonuclear Hartmann-Hahn spectroscopy. J Am Chem Soc 1985; 107: 2820-1.

[38] Rance M. Improved techniques for homonuclear rotating-frame and isotropic mixing experiments. J Magn Reson 1987; 74: 557- 64.

[39] Kadkhodaei M, Hwang TL, Tang J, Shaka AJ. A Simple Windowless Mixing Sequence to Suppress Cross Relaxation in TOCSY Experiments. J Magn Reson A 1993; 105: 393-9.

[40] Hwang TL, Shaka AJ. Water suppression that works. Excitation sculpting using arbitrary waveforms and pulsed field gradients. J Magn Reson A 1995; 112: 275-9

[41] Bodenhausen G, Ruben DJ. Natural abundance nitrogen-15 NMR by enhanced heteronuclear spectroscopy. Chem Phys Lett 1980; 69: 185-9.

[42] Bax A, Ikura M, Kay LE, Torchia DA, Tschudin R. Comparison of different modes of two-dimensional reverse-correlation NMR for the study of proteins. J Magn Reson 1990; 86: 304-18.

[43] Moy FJ, Sheraga HA, Liu JF, Wu R, Montelione G. Conformational characterization of a single-site mutant of murine epidermal growth factor (EGF) by $1 \mathrm{H}$ NMR provides evidence that leucine-47 is involved in the interaction with the EGF receptor. Proc Natl Acad Sci USA 1989; 86: 9836-40.

[44] Cornilescu G, Delaglio F, Bax A. Protein backbone angle restraints from searching a database for chemical shift and sequence homology. J Biomol NMR 1999; 13: 289-302.

[45] Güntert P, Mumenthaler C, Wüthrich K. Torsion angle dynamics for NMR structure calculation with the new program DYANA. J Mol Biol 1997; 273: 283-98.

[46] Laskowski RA, MacArthur MW, Moss DS, Thornton JM. PROCHECK : a program to check the stereochemical quality of protein structures. J Appl Cryst 1993; 26: 283-91.
[47] Koradi R, Billeter M, Wüthrich K. MOLMOL: a program for display and analysis of macromolecular structures. J Mol Graphics 1996; 14: 51-5.

[48] Dominguez C, Boelens R, Bonvin AM. HADDOCK: a proteinprotein docking approach based on biochemical or biophysical information. J Am Chem Soc 2003; 125: 1731-7.

[49] Hubbard SJ, Thornton JM. Department of Biochemistry and Molecular Biology, University College London 1993.

[50] Mayer M, Meyer B. Group Epitope Mapping by Saturation Transfer Difference NMR to identify Segments of a Ligand in Direct Contact with a Protein Receptor J. Am Chem Soc 2001; 123 : 6108-17.

[51] Thomas CC, Deak M, Alessi DR, van Aalfen DMF. Highresolution structure of the Pleckstrin Homology domain of Protein Kinase B/Akt bound to Phosphatidylinositol $(3,4,5)$-Triphosphate. Curr Biol 2002; 12: 1256-62.

[52] Ferguson KM, Kavran JM, Sankaran VG, et al. Structural basis for discrimination of 3-phosphoinositides by Pleckstrin Homology domains. Mol Cell 2000; 6: 373-384.

[53] Wüthrich K. NMR of Proteins and Nucleic Acids, New York: Wiley 1986.

[54] Ni F. Recent developments in transferred NOE methods. Progr NMR Spectrosc 1994; 26: 517-606.

[55] French SW, Shen RR, Koh PJ, Malone CS, Mallick P, Teitell MA. A modeled hydrophobic domain on the TCL1 oncoprotein mediate association with AKT at the cytoplasmic membrane. Biochemistry 2002; 41: 6376-82

[56] Kunstle G, Laine J, Pierron G, et al. Identification of Akt association and oligomerization domain of the Akt kinase coactivator TCL1. Mol Cell Biol 2002; 22: 1513-25.

[57] Kumar CC, Madison V. Akt crystal structure and Akt-specific inhibitors. Oncogene 2005; 24: 7493-501.

[58] Barnett SF, Defeo-Jones D, Fu S, et al. Identification and characterization of pleckstrin-homology-domain-dependent and isoenzyme-specific Akt inhibitors. Biochem J 2005; 385: 399-408.

[59] Hajduk PJ, Greer J. A decade of fragment-based drug design: strategic advances and lessons learned. Nat Rev Drug Discov 2007; 6: 211-9.

[60] Huth JR, Park C, Petros AM, et al. Discovery and design of novel HSP90 inhibitors using multiple fragment-based design strategies. Chem Biol Drug Des 2007; 70: 1-12.

[61] Huang BX, Kim HY. Probing Akt-Inhibitor Interaction by Chemical Cross-Linking and Mass Spectrometry. J Am Soc Mass Spectrom 2009, Apr 16 [Epub ahead of print].

[62] Wallace AC, Laskowski RA, Thornton JM. LIGPLOT: A program to generate schematic diagrams of protein-ligand interactions. Prot Eng 1995; 8: 127-34

This is an open access article licensed under the terms of the Creative Commons Attribution Non-Commercial License (http://creativecommons.org/licenses/ by$\mathrm{nc} / 3.0 /$ ) which permits unrestricted, non-commercial use, distribution and reproduction in any medium, provided the work is properly cited. 